\title{
An adolescent with an altered state of mind
}

\author{
Samuele Naviglio trainee paediatrician ${ }^{1}$, Duccio Papanti trainee psychiatrist $^{1}$, Valentina Moressa \\ trainee paediatrician ${ }^{1}$, Alessandro Ventura professor of paediatrics ${ }^{12}$ \\ ${ }^{1}$ Department of Medical, Surgical, and Health Sciences, University of Trieste, 34149 Trieste, Italy; ${ }^{2}$ Institute for Maternal and Child Health IRCCS \\ "Burlo Garofolo," Trieste, Italy
}

\begin{abstract}
A 17 year old previously healthy adolescent presented to the emergency department with severe headache, vomiting, and an altered state of mind. His mother reported that he had returned home one hour before, looking confused and agitated; afterwards he mentioned a worsening headache and had vomited twice. On arrival at the emergency department he was conscious but drowsy and slow in answering simple questions. He reported frontal headache (8/10 on a visual analogue scale) and photophobia, and he was unable to stand unassisted. He was afebrile, his heart rate was 170 beats/min, and his blood pressure was $132 / 80 \mathrm{~mm} \mathrm{Hg}$. His pupils were mydriatic and poorly reactive to light. The remainder of the physical examination was unremarkable. He denied taking any drugs or medication, and a urine screen test was negative for cannabinoids, opioids, amphetamines, benzodiazepines, ethanol, and cocaine.

Computed tomography of the brain and a basic set of blood tests were performed, and all results were normal. On further questioning by his parents he admitted having smoked "herbal incense" with friends in the afternoon, after which he reported having experienced visual and auditory hallucinations.
\end{abstract}

\section{Questions}

1. Which diagnosis does this story suggest?

2. What potentially serious complications should be considered?

3. How could you confirm the diagnosis?

4. How should this patient be managed?

\section{Answers}

\section{Which diagnosis does this story suggest? Short answer}

Acute intoxication by an emerging drug of misuse, probably a synthetic cannabinoid. Clues to the diagnosis include acute onset, otherwise unexplained, central nervous system and autonomic disturbances in a healthy young person with negative drug screening tests and a history of smoking herbal incense.

\section{Long answer}

The evaluation of an adolescent or young adult presenting to the emergency department with a change of mental status can be challenging. The differential diagnosis is extensive, comprising psychiatric conditions and medical conditions, including cerebrovascular events, unreported trauma, intoxication, carbon monoxide poisoning, epileptic disorders, and endocrine or metabolic disorders (including inborn errors of metabolism), as well as infectious, autoimmune, and neoplastic diseases. ${ }^{12}$

Although all these possible causes should be considered, acute intoxication by a substance of misuse should always be a strong contender in a previously healthy adolescent presenting with acute onset change of mental status, especially when coupled with autonomic signs and symptoms. This possibility should always be evaluated clinically and by means of a history focused on drug consumption. Drug screening tests may detect the presence of the most common substances of misuse, but positive and negative results do not absolutely confirm or refute a diagnosis, and further evaluation is needed. A positive result does not necessarily mean that the presenting signs and symptoms are caused by the substance detected, which could have been taken some days before and be still present in the urine, but not be related to the observed symptoms. However, it may serve as an indicator of current intake of substances by the patient, who may often take multiple drugs. ${ }^{34}$ By contrast, a negative result does not rule out intoxication by other, undetected, psychoactive substances. In this respect, particular attention should be paid to intoxication by emerging drugs of misuse, a vast class of chemically diverse psychoactive substances that go largely undetected by conventional immunoassay drug screen tests. ${ }^{4}$

"Emerging drugs of misuse" or "new psychoactive substances" are umbrella terms for all psychoactive substances not under 
international control that pose a health threat. ${ }^{5}$ The exact number of these drugs is unknown. In December 2013 the number of such substances reported to the United Nations Office on Drug and Crime reached 348, but this is probably an underestimate because new molecules are constantly appearing on the market. ${ }^{6}$ In the past decade, the use of these drugs has grown rapidly, especially among adolescents and young adults, and it is a global phenomenon. ${ }^{5}$ In the European Union almost 5\% of 15-24 year olds reported having tried a new psychoactive substance at least once (range: $0.3 \%$ in Malta to $16.3 \%$ in Ireland), ${ }^{7}$ and even higher figures have been reported in the United States. ${ }^{8}$

Despite often being perceived as "safe" by consumers, ${ }^{8}$ their use is associated with a high risk of serious toxic effects, as well as a parallel increase in emergency department visits and calls to poison control centres. ${ }^{3910}$ In addition, doctors are still unfamiliar with these substances. ${ }^{11}$ Common classes of new psychoactive substances include synthetic cannabinoids, synthetic cathinones ("bath salts," including mephedrone, methylone, and methylenedioxypyrovalerone), piperazines (like benzylpiperazine), phenethylamines, tryptamines, phencyclidine derivatives, as well as various plant derived psychoactive substances like kratom (Mitragyna speciosa) and Salvia divinorum. Synthetic cannabinoids and synthetic cathinones are the most commonly encountered new psychoactive substances in clinical practice, and possibly also the most dangerous. ${ }^{5}$ Synthetic cannabinoids, also known as "spice products," are designer drugs (substances developed to avoid existing drug control measures) with very strong cannabis-like effects. They are sold in "head shops," in convenience stores, and on the internet, often under catchy names like "Spice," "K2," "Genie," and "Black Mamba." They are usually disguised as herbal incenses, potpourris, or room aromatisers, often labelled as "not for human consumption," and they are commonly smoked or ingested.

\section{What potentially serious complications should be considered?}

\section{Short answer}

Synthetic cannabinoids can cause severe neurological and psychiatric toxic effects as well as injury to other organ systems, including myocardial infarction, cardiac dysrhythmia, hypokalaemia, hyperthermia, and acute kidney injury. A small number of deaths have also been reported.

\section{Long answer}

Acute intoxication by synthetic cannabinoids has been associated with serious toxicity and even some deaths. ${ }^{12}$ Synthetic cannabinoids act as potent agonists on cannabinoid receptors, whereas $\Delta^{9}$-tetrahydrocannabinol, the major psychoactive compound of cannabis, is only a partial agonist. This fact may account for their greater potential for toxicity, with any misuse easily turning into an overdose..$^{13}$ Moreover, synthetic cannabinoids also act on other neurotransmitters, which may explain some of the differences between intoxication with cannabis and with synthetic cannabinoids. For example, inhibition of $\gamma$-aminobutyric acid receptors may cause anxiety, agitation, and seizures, whereas the activation of serotonin receptors and the inhibition of monoamine oxidases may be responsible for hallucinations and the occurrence of serotonin syndrome-like signs and symptoms. ${ }^{14}{ }^{15}$ Furthermore, in marketed products, synthetic cannabinoids may be deliberately admixed with psychoactive herbs, ${ }^{16}$ or with other substances such as $\beta$ agonists like clenbuterol, ${ }^{17}{ }^{18}$ opioid agonists, ${ }^{19}$ and benzodiazepines like phenazepam, ${ }^{20}$ thus possibly creating complex clinical presentations.

Although acute intoxication by synthetic cannabinoids has some similarities to intoxication by high dose cannabis, it can be more intense and associated with more prominent sympathomimetics signs. The most commonly reported symptoms and signs are confusion, agitation, irritability, drowsiness, tachycardia, hypertension, diaphoresis, mydriasis, and hallucinations. ${ }^{21}$ Other neurological and psychiatric effects include seizures, suicidal ideation, aggressive behaviour, and psychosis. ${ }^{22}$ Ischaemic stroke has also been reported. ${ }^{23}$ Gastrointestinal toxicity may cause xerostomia, nausea, and vomiting. Severe cardiotoxic effects have been described, including myocardial infarction, tachyarrhythmia, and bradyarrhythmia. ${ }^{24}$ Other potentially serious effects include hypokalaemia, hyperglycaemia, hyperthermia, rhabdomyolysis, ${ }^{25}$ and acute kidney injury. ${ }^{26} \mathrm{An}$ addiction syndrome and withdrawal symptoms have been reported in habitual users. ${ }^{27}$

Synthetic cannabinoid intoxication should therefore be included in the differential diagnosis of patients, most commonly adolescents or young adults, presenting with an acute and otherwise unexplained alteration of the central nervous system associated with autonomic disturbances. Other situations in which a high index of suspicion should be maintained include atypical presentations, such as acute unexplained kidney injury or myocardial infarction in a healthy young person.

\section{How could you confirm the diagnosis? Short answer}

Synthetic cannabinoids are not usually detected by conventional drug screening tests. In the absence of a positive history, advanced tests like liquid chromatography-tandem mass spectrometry may identify the substance, but these are not generally available in the acute setting.

\section{Long answer}

The most important step is to obtain a precise history, but this is not always possible because of the patient's conditions or reticence. Focused questions, such as "have you smoked or ingested any incense, potpourri, or herbal product?," may help avoid unnecessary investigations and direct management. Common street names for synthetic cannabinoids are Spice, K2, Skunk, Incense, Bliss, Fake Weed, Yucatan Fire, Genie, Moon Rocks, Zohai, and Black Mamba, ${ }^{28}$ whereas "bath salts" is a common name for synthetic cathinones. It is advisable to contact the local poison control centre, which may provide assistance in the acute setting and set up surveillance on the distribution of these substances. Synthetic cannabinoids, like other new psychoactive substances, are not usually detected by conventional drug screening tests. Advanced tests like gas chromatography or liquid chromatography-tandem mass spectrometry can be performed on a blood or urine specimen at reference laboratories, but they are not generally available in the acute setting and are used mainly for forensic investigations. If these tests are requested, the specimen should be collected as early as possible, preferably during the first 12 hours, because these drugs are generally metabolised rapidly. Finally, some synthetic cannabinoids are not detected even with advanced testing because most laboratories have only a limited library of reference compounds, and newer molecules may not be included. 


\section{How should this patient be managed? Short answer}

Intoxicated patients should be observed until recovery and should undergo further evaluations, including a battery of basic blood tests and electrocardiography. Treatment is mainly supportive.

\section{Long answer}

Management of acute intoxication by synthetic cannabinoids should follow the general principles of drug misuse emergencies. ${ }^{29}$ After stabilisation, a complete physical and neurological examination should be performed. Patients should be observed until recovery. Vital signs should be monitored, including temperature, because hyperthermia is an ominous sign that may warrant active patient cooling and expert consultation. A battery of blood tests, including glucose, electrolytes, creatinine, transaminases, creatine phosphokinase, and cardiac troponin, should be requested, as well as electrocardiography, to screen for possible complications and toxic effects on organ systems. The simultaneous misuse of other drugs should also be actively investigated. Drug decontamination or enhanced elimination is not usually possible, and there is no specific antidote. Intoxications are commonly short lived (6-24 h), and management is mainly supportive. Placement in a quiet, dim environment can be helpful, with intravenous fluids as needed and long acting benzodiazepines in case of agitation. More severe psychiatric symptoms (such as psychotic symptoms, aggressive behaviour) may warrant a psychiatric consultation. If antipsychotic drugs are used, the QT interval should be monitored. A psychiatric consultation should always be arranged in the follow-up.

\section{Patient outcome}

The patient was admitted for observation and intravenous rehydration with normal saline. The results of a battery of blood tests and electrocardiography were normal. He made a full recovery in the next 12 hours. A blood specimen sent for gas chromatography detected the presence of JWH-018 and JWH-122, two common synthetic cannabinoids.

Competing interests: We have read and understood BMJ policy on declaration of interests and declare that we have no competing interests. Provenance and peer review: Not commissioned; externally peer reviewed.

Patient consent obtained.

Katz ER, Chapman LL, Chun TH. Psychiatric emergencies. In: Fleisher GR, Ludwig S, eds. Textbook of pediatric emergency medicine. 6th ed. Lippincott Williams \& Wilkins, 2010.

2 Sikich L. Diagnosis and evaluation of hallucinations and other psychotic symptoms in children and adolescents. Child Adolesc Psychiatr Clin N Am 2013:22:655-73.
3 Substance Abuse and Mental Health Services Administration. Drug Abuse Warning Network, 2011. National estimates of drug-related emergency department visits. 2013. http://archive.samhsa.gov/data/2k13/DAWN2k11ED/DAWN2k11ED.htm.

4 Kersten BP, McLaughlin ME. Toxicology and management of novel psychoactive drugs. $J$ Pharm Pract 2014; published online 26 Sep, doi:10.1177/0897190014544814.

5 United Nations Office on Drug and Crime. World drug report 2013. 2013. www.unodc.org/ unodc/secured/wdr/wdr2013/World_Drug_Report_2013.pdf.

6 United Nations Office on Drug and Crime. World drug report 2014. 2014. www.unodc.org documents/wdr2014/World_Drug_Report_2014_web.pdf.

7 Gallup Organization. Youth attitudes on drugs: analytical report. European Commission, 2011. http://ec.europa.eu/public_opinion/flash/fl_330_en.pdf.

8 Johnston LD, O'Malley PM, Bachman JG, Schulenberg JE, Miech RA. Monitoring the future national survey results on drug use, 1975-2013. Vol. I. Secondary school students. Institute for Social Research, 2014. http://monitoringthefuture.org/pubs/monographs/mtfvol1_2013.pdf.

9 Substance Abuse and Mental Health Services Administration. Center for Behavioral Health Statistics and Quality. Update: drug-related emergency department visits involving synthetic cannabinoids. 2014. www.samhsa.gov/data/sites/default/files/SR-1378/SR-1378.pdf.

10 Bronstein AC, Spyker DA, Cantilena LR, Rumack BH, Dart RC. 2011 Annual report of the American Association of Poison Control Centers' National Poison Data System (NPDS): 29th annual report. Clin Toxicol (Phila) 2012;50:911-1164.

11 Lank PM, Pines E, Mycyk MB. Emergency physicians' knowledge of cannabinoid designer drugs. West J Emerg Med 2013;14:467-70.

12 Hoyte CO, Jacob J, Monte AA, Al-Jumaan M, Bronstein AC, Heard KJ. A characterization of synthetic cannabinoid exposures reported to the national poison data system in 2010 . Ann Emerg Med 2012;60:435-8.

13 Papanti D, Orsolini L, Francesconi G, Schifano F. "Noids" in a nutshell: everything you (don't) want to know about synthetic cannabimimetics. Adv Dual Diagnosis 2014;7:137-48.

14 Louh IK, Freeman WD. A "spicy" encephalopathy: synthetic cannabinoids as cause of encephalopathy and seizure. Crit Care 2014;18:553.

15 Wells DL, Ott CA. The "new" marijuana. Ann Pharmacother 2011;45:414-7.

16 Ogata J, Uchiyama N, Kikura-Hanajiri R, Goda Y. DNA sequence analyses of blended herbal products including synthetic cannabinoids as designer drugs. Forensic Sci Int 2013;227:33-41.

17 Ashton JC. Synthetic cannabinoids as drugs of abuse. Curr Drug Abuse Rev 2012;5:158-68.

18 Burlington County. (BCHD10-115) Public health advisory-evolving new drug abuse problem - synthetic marijuana. New Jersey Local Information Network Communications System. Health Alert Network. 2010.

19 Uchiyama N, Matsuda S, Kawamura M, Kikura-Hanajiri R, Goda Y. Two new-type cannabimimetic quinolinyl carboxylates, QUPIC and QUCHIC, two new cannabimimetic carboxamide derivatives, ADB-FUBINACA and ADBICA, and five synthetic cannabinoids detected with a thiophene derivative a-PVT and an opioid receptor agonist AH-7921 identified in illegal products. Forensic Toxicol 2013:31:223-40.

20 Park Y, Lee C, Lee H, Pyo J, Jo J, Lee J, et al. Identification of a new synthetic cannabinoid in a herbal mixture: 1-butyl-3-(2-methoxybenzoyl)indole. Forensic Toxicol 2013;31:187-96.

21 Hermanns-Clausen M, Kneisel S, Szabo B, Auwärter V. Acute toxicity due to the confirmed consumption of synthetic cannabinoids: clinical and laboratory findings. Addiction 2013;108:534-44.

22 Papanti D, Schifano F, Botteon G, Bertossi F, Mannix J, Vidoni D et al. "Spiceophrenia": a systematic overview of "Spice"-related psychopathological issues and a case report. Hum Psychopharmacol 2013;28:379-89.

23 Freeman MJ, Rose DZ, Myers MA, Gooch CL, Bozeman AC, Burgin WS. Ischemic stroke after use of the synthetic marijuana "spice." Neurology 2013;81:2090-3.

24 Mir A, Obafemi A, Young A, Kane C. Myocardial infarction associated with use of the synthetic cannabinoid K2. Pediatrics 2011;128:e1622-7.

25 Durand D, Delgado LL, de la Parra-Pellot DM, Nichols-Vinueza D. Psychosis and severe rhabdomyolysis associated with synthetic cannabinoid use. Clin Schizophr Relat Psychoses 2013; published online $21 \mathrm{Mar}$, doi:10.3371/CSRP.DUDE.031513.

26 Bhanushali GK, Jain G, Fatima H, Leisch LJ, Thornley-Brown D. AKI associated with synthetic cannabinoids: a case series. Clin J Am Soc Nephrol 2013;8:523-6.

27 Zimmermann US, Winkelmann PR, Pilhatsch M, Nees JA, Spanagel R, Schulz K. Withdrawal phenomena and dependence syndrome after the consumption of "spice gold." Dtsch Arztebl Int 2009;106:464-7.

28 Washington State University Alcohol and Drug Counseling, Assessment, and Prevention Services. http://adcaps.wsu.edu/drugs101/basic-descriptors/.

29 Nelson ME, Bryant SM, Aks SE. Emerging drugs of abuse. Emerg Med Clin North Am 2014:32:1-28

\section{Cite this as: BMJ 2015;350:h299}

@ BMJ Publishing Group Ltd 2015 